\title{
Announcing the 7th World Meeting on Pharmaceutics, Biopharmaceutics and Pharmaceutical Technology
}

\author{
Juergen Siepmann ${ }^{1,2}$
}

Received 3 June 2009; accepted 3 June 2009; published online 17 June 2009

\section{MARCH 8-11, 2010, MALTA}

In continuation of the successful past scientific meetings in Budapest, Paris, Berlin, Florence, Geneva, and Barcelona, the 7th World Meeting on Pharmaceutics, Biopharmaceutics, and Pharmaceutical Technology will be held in Malta in 2010. This conference has gained an ever increasing impact among the pharmaceutical scientists. With close to 1,000 submitted abstracts and 1,400 participants, a new record was achieved in Barcelona.

The 7th World Meeting will be jointly organized by the APV (German "International Association for Pharmaceutical Technology"), APGI (French "Association de Pharmacie Galénique Industrielle") and ADRITELF (Italian "Associazione Docenti Ricercatori Italiani di Tecnologie e Legislazione Farmaceutiche"), together with 15 other pharmaceutical societies.

Due to the great interest in the newly introduced symposia on industrial-related topics in Barcelona, this concept will be continued and even extended in Malta: from Tuesday to Thursday, two of the four parallel oral presentation sessions will be provided by invited speakers from industry and academia on the following topics: "Biopharmaceuticals," "Progress in Solid Dosage Form Development and Manufacturing," "Modified Oral Release," "Modern Devices," "Nucleic Acid Design and Delivery," "Process Design and Control," and "Challenges in Paediatric Dosage Form Development."

Prof. Thomas Kissel (University of Marburg, Germany), Prof. Kostas Kostarelos (University of London, UK), and Prof. Jean-Paul Remon (University of Ghent, Belgium) will give comprehensive plenary lectures. Worldwide-recognized invited speakers include: Dr. Daniel Anderson (MIT, USA), Prof. JeanPierre Benoit (University of Angers, France), Dr. Joerg Breitenbach (Soliqs, Germany), Dr. Per Djupesland (OptiNose, Norway), Dr. Mike Eaton (UCB, Belgium), Prof. Henderik Frijlink (University of Groningen, The Netherlands), Prof. Andrea Gazzaniga (University of Milan, Italy), Prof. Lisbeth

\footnotetext{
${ }^{1}$ College of Pharmacy, University of Lille, Lille, France.

${ }^{2}$ To whom correspondence should be addressed. (e-mail: juergen. siepmann@univ-lille2.fr)
}

Illum (IDentity, UK), Dr. Bruno Leclercq (FMC BioPolymer, Belgium), Dr. Hans Christian Mahler (Roche, Switzerland), Prof. Nicholas Peppas (University of Texas at Austin, USA), Dr. Stephen Perrett (Eurand, Italy), Dr. Norbert Poellinger (Glatt, Germany), Prof. Michael Repka (University of Mississippi, USA), Dr. Steven Shire (Genentech, USA), Prof. Klaus-Juergen Steffens (University of Bonn, Germany), Dr. Karl Wagner (Boehringer Ingelheim, Germany), and Dr. Mathias Walther (Pfizer, UK).

In addition to these industrial sessions, the 7th World Meeting, like its predecessors, will offer a great number of oral sessions and poster presentations: young and established scientists from all over the world will have the opportunity to present their work, learn about new scientific findings and talk about their experience with colleagues on a broad range of topics related to pharmaceutics, biopharmaceutics, and pharmaceutical technology.

The meeting will help bridge the gap between fundamental academic research and industrial applications, offering the opportunity to initiate fruitful cooperation between university and industry.

The 7th World Meeting is accompanied by ResearchPharm ${ }^{\circledR}$ an international exhibition supporting research and development. Excipients, analytical equipment, and laboratory-scale production equipment are part of the exhibition. Furthermore, many scientific societies and organizations will be presenting information on scientific and technical services. ResearchPharm $\AA$ is an integral part of this meeting and provides opportunities for the exchange of news, research findings, and current technologies.

Malta is a group of islands in the heart of the Mediterranean Sea. It has been inhabited since around 5200 BC. A significant prehistoric civilization existed on the islands prior to the arrival of the Phoenicians, who named the main island "Malat," meaning "safe haven." The islands were for centuries the seat of the Order of Knights of the Hospital of St. John and then part of the British Empire. Malta became independent in 1964.

For more detailed information, visit the meeting's website at http://www.worldmeeting.org or email: info@ worldmeeting.org. 